\title{
A Microscopy Study on the Origin of Asterism in Almandine-Pyrope Garnets
}

\author{
Maxime J-F Guinel, M. Grant Norton, and David F. Bahr
}

Washington State University, School of Mechanical and Materials Engineering, PO Box 642920, Pullman, WA 99164-2920, U.S.A.

The garnet group of minerals is especially characteristic of metamorphic rocks and is very widespread; however, there are only few known occurrences of asteriated garnets (Idaho, India, Sri Lanka, and Tanzania) [1]. Gem lovers collect such stones as rarities or as small objets d'art.

Asteriated purplish-red garnets from Emerald Creek, Idaho, were the object of this study. They are usually found in isolated, granular crystals, often in the form of a perfect rhombic dodecahedron as shown in Fig. 1(a). The garnet structure is cubic (Ia3d) and its habits can be dodecahedral, icositetrahedral (less common), and combinations of both. The asterism is at its best advantage for stones that are cut and polished in the cabochon style and illuminated by a source of parallel light, as illustrated in Fig. 1(b and c). What makes the asterism in garnet special is the fact that stones may show both the 4 and 6 rayed stars. Four and six fold asterism is produced by submicron acicular inclusions of rutile, and can be considered as multiple chatoyance brought about by the scattering of light by these needles and the refractive index of the stone surface [1,2]. The aim of this study is to determine the origin of the 4 and 6 ray asterisms and the microstructural factors affecting their quality.

The garnets studied are of the type almandine-pyrope (pyralspite series) with composition $\left(\mathrm{Fe}_{2.4} \mathrm{Mg}_{0.5} \mathrm{Mn}_{0.1}\right) \mathrm{Al}_{2} \mathrm{Si}_{3} \mathrm{O}_{12}$, determined using quantitative electron probe microanalysis. Natural garnets invariably contain inclusions. Numerous large ilmenite $\left(\mathrm{FeTiO}_{3}\right)$ crystals, in the form of flakes of hundreds of micrometers across, were present throughout some of the garnets studied. Electron diffraction confirmed their structures, as shown in Fig. 2. Microscopic examination reveals a singular kind of interior with an inclusion system of closely crowded, very fine, acicular crystals, with a definite angular relation as illustrated in Fig. 3, for a 4 rayed star. The needles intersect to form angles of $\sim 70^{\circ}$ and $\sim 110^{\circ}$. Predominantly, the rutile needles were found to have diameters in the order of $100 \mathrm{~nm}$ as shown in Fig. 4(a). Occasionally much longer needles with diameters of 100 's of nm were found, as illustrated in Fig. 4(b). Electron diffraction showed that the needles were rutile, the stable phase of $\mathrm{TiO}_{2}$. A HRTEM image of a garnet/rutile interface is shown in Fig. 4(c). Substantial misfit results and moiré fringes were observed. Some needles appeared to be internally twinned, most probably to help alleviate the lattice strain due to garnet/rutile mismatch. The small diameter of the rutile needles (less than $200 \mathrm{~nm}$ in most cases) with respect to the wavelength of light, combined with the presence of numerous large inclusions of ilmenite, with no preferred orientation, may be the cause of weakness of the asterism in some of the garnets studied.

\section{References}

[1] K. Schmetzer et al., J. Gemm. 28 (2002) 13.

[2] A. J. Wallcott, Field Museum of Natural History 12 (1937) 39.

[3] HRTEM data were collected at the EMSL, a national scientific user facility sponsored by the DOE, located at Pacific Northwest National Laboratory. 

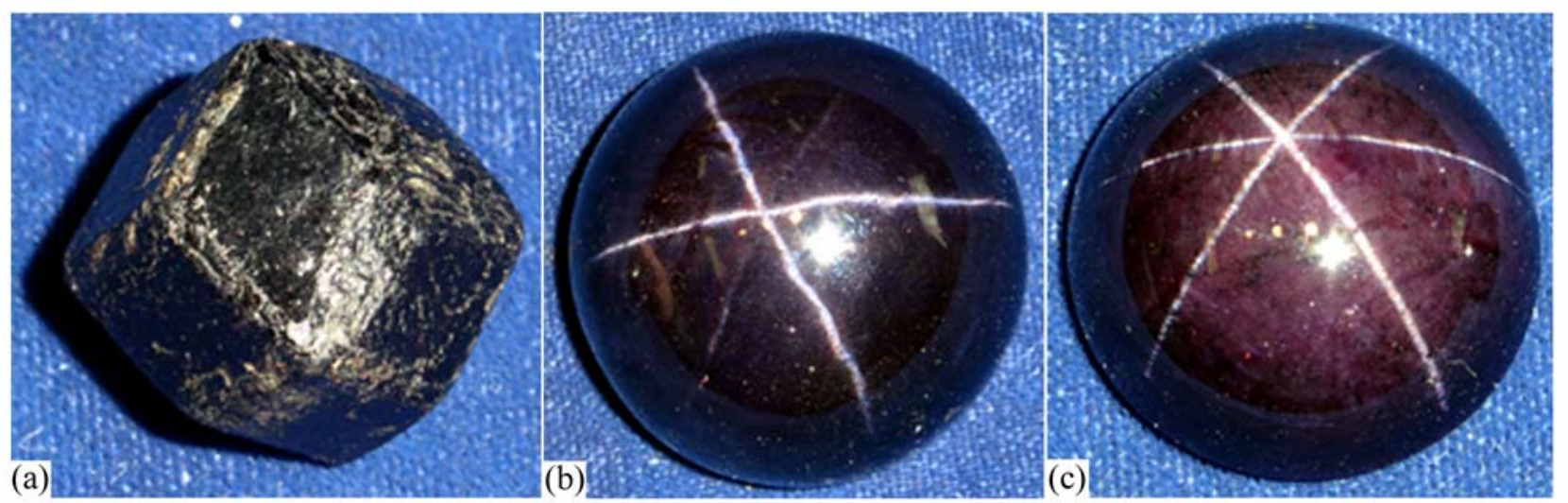

Fig. 1. (a) Garnet crystal (9 cts) exhibiting the rhombic dodecahedral habit. Asteriated garnets cut en cabochon revealing (b) a four-rayed and (c) a six-rayed star, weighting 110 and 46 cts, respectively.

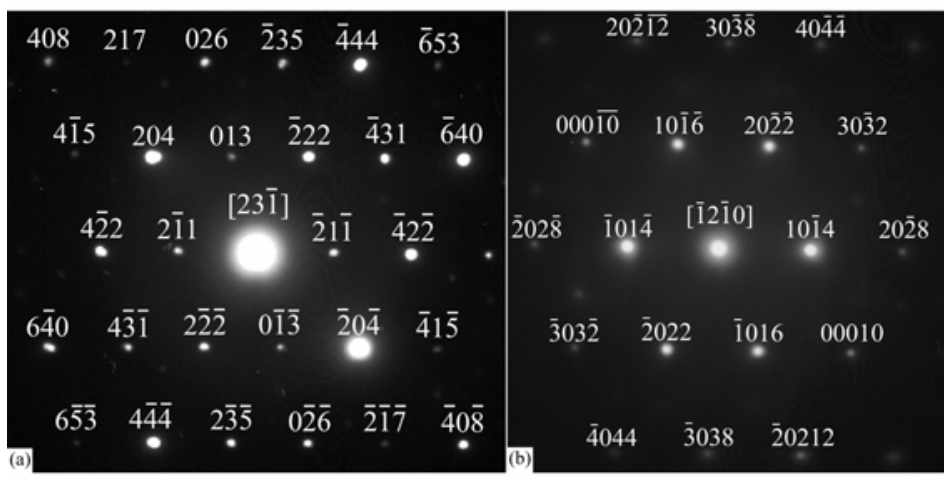

Fig. 2. (a) DP of the garnet matrix at the [231] zone axis. (b) DP of an ilmenite inclusion at the [1]2 10$]$ zone axis.

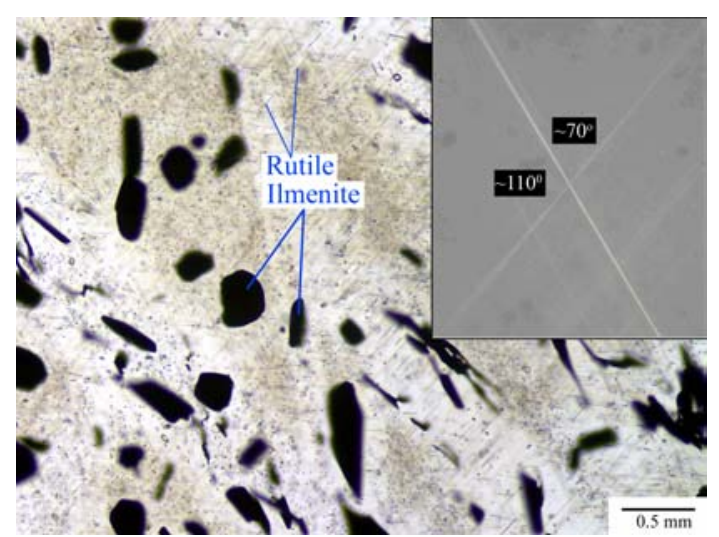

Fig. 3. Optical micrograph. The insert is a reflected light micrograph showing two acicular inclusions of rutile.

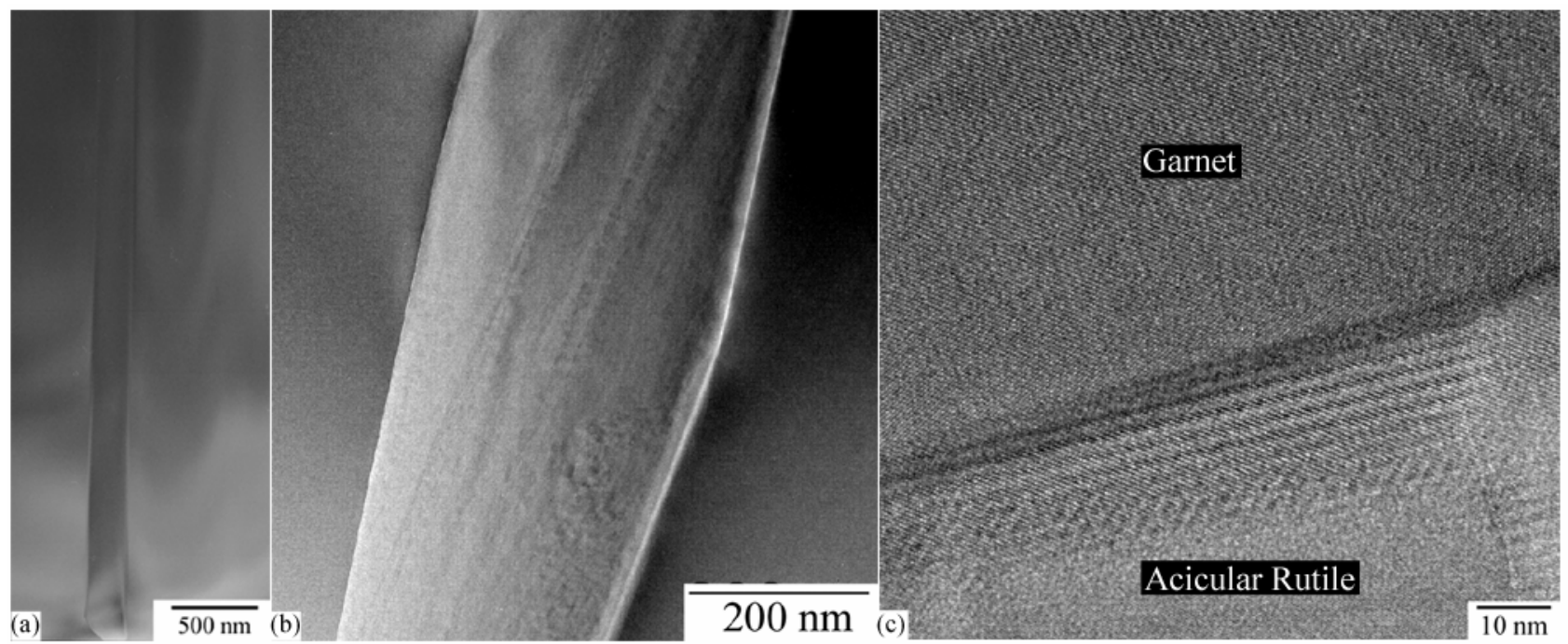

Fig. 4. (a) TEM and (b) HRTEM images of rutile needles embedded in their host garnet. (c) HRTEM image of the interface between the garnet matrix and an acicular crystal of rutile. 